\title{
Transient heat transfer at fluid flow in a thick-walled pipeline
}

\author{
Tomasz Sobota ${ }^{1, *}$, Dawid Taler $^{2}$, and Szczepan Lubecki ${ }^{3}$ \\ ${ }^{1}$ Cracow University of Technology, Institute of Thermal Power Engineering, Faculty of Mechanical Engineering, \\ Al. Jana Pawła II 37, 31-864 Cracow, Poland \\ ${ }^{2}$ Cracow University of Technology, Institute of Thermal Engineering and Air Protection, Faculty of Environmental \\ Engineering, ul. Warszawska 24, 31-155 Cracow, Poland \\ ${ }^{3}$ BIPROTECH LLC, ul. Kamieńskiego 47, 30-644 Cracow, Poland
}

\begin{abstract}
The work aims to determine the transient temperature distribution of the medium and the pipeline wall using the finite difference method. Time courses of the temperature of the flowing medium and pipeline walls caused by a step change in temperature of the medium at the pipeline inlet, obtained by the numerical method, were compared with the courses calculated using strict analytical formulas. The numerical method of determining the transient distribution of temperature of medium and pipeline wall can be used in the analysis of heating and cooling of heating or steam pipelines with any changes in time of mass flow rate of the flowing medium or temperature of the medium at the inlet to the pipeline..
\end{abstract}

\section{Introduction}

During start-up and shutdown of power units, heating and cooling of pipelines, in particular, the pipeline connecting the boiler with the turbine, is an important issue. The temperature course of the medium is important not only because of the thermal stresses in the pipeline wall but also because of the stresses in the fittings installed on the pipeline [1-16]. In the case of steam or gases, the temperature changes along the pipeline length are higher due to the lower density and specific heat of the medium. Large wall thicknesses and considerable lengths also contribute to a significant reduction in the temperature of superheated steam in pipelines.

\section{Mathematical formulation of the problem}

The temperature changes of the medium and the pipeline wall are described by the following equations

$$
\begin{gathered}
\tau_{c z} \frac{\partial T_{c z}}{\partial t}+\frac{1}{N_{c z}} \frac{\partial T_{c z}}{\partial z^{+}}=T_{s c}-T_{c z}, \\
\tau_{M} \frac{\partial T_{s c}}{\partial t}=T_{c z}-T_{s c}
\end{gathered}
$$

The boundary condition and initial conditions are in the form

$$
\begin{gathered}
\left.T_{c z}\right|_{z=0}=T_{0}+f(t), \\
\left.T_{c z}\right|_{t=0}=T_{0}, \\
\left.T_{s c}\right|_{t=0}=T_{0} .
\end{gathered}
$$

In Eqs. (1-5) the following designations have been adopted: $T_{c z}$ i $T_{s c}$ - fluid and wall temperature in ${ }^{\circ} \mathrm{C}, t$ time in $\mathrm{s}, z^{+}=z / L_{r}-\quad$ dimensionless Cartesian coordinate, $L_{r}$ - steam pipeline length in $\mathrm{m}, T_{0}$ - constant initial temperature of the fluid in ${ }^{\circ} \mathrm{C}, f(t)$ - fluid temperature changes in time at pipeline inlet in ${ }^{\circ} \mathrm{C}$. The number of heat transfer units $N_{c z}$, the fluid time constant $\tau_{c z}$ and steam pipeline wall time constant $\tau_{M}$ are defined by the following formulae:

$$
\begin{gathered}
N_{c z}=\frac{h_{c z} A_{i n}}{\dot{m}_{c z} c_{p c z}}=\frac{h_{c z} U_{i n} L_{r}}{A_{c z} w_{c z} \rho_{c z} c_{p c z}}, \\
\tau_{M}=\frac{m_{m} c_{m}}{h_{c z} A_{w}}=\frac{A_{m} L_{r} \rho_{m} c_{m}}{h_{c z} A_{i n}}, \\
\tau_{c z}=\frac{m_{c z} c_{p c z}}{h_{c z} A_{i n}}=\frac{A_{c z} L_{r} \rho_{c z} c_{p c z}}{h_{c z} A_{i n}},
\end{gathered}
$$

where $h_{c z}$ denotes heat transfer coefficient on the inner surface of the pipeline in $\mathrm{W} /\left(\mathrm{m}^{2} \mathrm{~K}\right), A_{\text {in }}=U_{w} \cdot L_{r}$ - inner surface area of the pipeline in $\mathrm{m}^{2}, \dot{m}_{c z}=A_{c z} w_{c z} \rho_{c z}$ - fluid mass flow rate in $\mathrm{kg} / \mathrm{s}, \rho_{c z}$ - fluid density in $\mathrm{kg} / \mathrm{m}^{3}, w_{c z}-$ velocity of the fluid flowing the pipeline in $\mathrm{m} / \mathrm{s}, c_{p c z}-$ fluid specific heat in $\mathrm{J} /(\mathrm{kgK}), m_{m}=A_{m} L_{r} \rho_{m}$ - mass of the pipeline in $\mathrm{kg}, \rho_{m}-$ density of the pipeline material in $\mathrm{kg} / \mathrm{m}^{3}, c_{m}-$ specific heat of the pipeline material in $\mathrm{J} /(\mathrm{kgK}), U_{\text {in }}=\pi d_{\text {in }}$ - inner circumference of the pipeline in $\mathrm{m}, A_{c z}=\pi\left(d_{i n}\right)^{2} / 4$ - cross-sectional area of the channel occupied by the fluid in $\mathrm{m}^{2}, A_{m}=\pi\left(d_{\text {out }}^{2}-d_{\text {in }}^{2}\right) / 4-$ cross-sectional area of the pipeline wall $\mathrm{w} \mathrm{m}^{2}$.

The Eqs. (1-2) have been derived with the assumption that the pipeline wall is thermally insulated on the external surface. Also, it has been assumed that the

\footnotetext{
*Corresponding author: tsobota@mech.pk.edu.pl
} 
distribution of temperature and fluid velocity in the cross-section of the pipeline does not depend on the radius. Due to the complexity of the problem described by the Eqs. (1-5), numerical methods, e.g. presented in the paper [17], must be used to determine the transient temperature of the medium and the pipeline. The initialboundary value problem (1-5) was solved with the explicit finite differences method. Fig. 1 shows a diagram of the differential grid for the calculation of the temperature distribution of the medium and the pipeline.

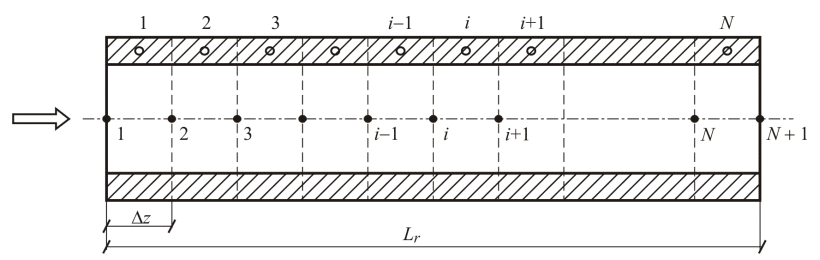

Fig. 1. Diagram of the finite difference grid

Applying the explicit finite differences method to the solution of the initial boundary problem (1-5), it is obtained

$$
\begin{gathered}
\tau_{c z} \frac{T_{c z, i+1}^{n+1}-T_{c z, i+1}^{n}}{\Delta t}+\frac{1}{N_{c z}} \frac{T_{c z, i+1}^{n}-T_{c z, i}^{n}}{\Delta z^{+}}= \\
=T_{s c, i}^{n}-\frac{T_{c z, i}^{n}+T_{c z, i+1}^{n}}{2}, \\
\tau_{M} \frac{T_{s c, i}^{n+1}-T_{s c, i}^{n}}{\Delta t}=\frac{T_{c z, i}^{n}+T_{c z, i+1}^{n}}{2}-T_{s c, i}^{n} \\
T_{c z, i}^{0}=T_{s c, i}^{0}=T_{0}, \\
T_{c z, 1}^{n}=f(n), \quad i=1, \ldots, N \quad n=0,1,2, \ldots,
\end{gathered}
$$

where $t_{n}=n \cdot \Delta t, \Delta t-$ denotes the time step in s, and $\mathrm{z} \Delta z^{+}$ $=\Delta z / L_{r}$ is dimensionless co-ordinate.

After solving the equations (9-10) in respect to $T_{c z, i+1}^{n+1}$ and $T_{s c, i}^{n+1}$ it is obtained

$$
\begin{gathered}
T_{c z, i+1}^{n+1}= \\
=T_{c z, i+1}^{n}-\frac{\Delta t}{\tau_{c z} N_{c z}}\left(\frac{T_{c z, i+1}^{n}-T_{c z, i}^{n}}{\Delta z^{+}}-T_{s c, i}^{n}+\frac{T_{c z, i}^{n}+T_{c z, i+1}^{n}}{2}\right) \\
T_{s c, i}^{n+1}=T_{s c, i}^{n}+\frac{\tau_{M}}{\Delta t}\left(\frac{T_{c z, i+1}^{n}+T_{c z, i}^{n}}{2}-T_{s c, i}^{n}\right)
\end{gathered}
$$

$i=1, \ldots, N, \quad n=0,1,2, \ldots$

In order to ensure stability of calculations using Eqs. (13-14), the Courant condition $[4,5]$ must be met

$$
\frac{w_{i} \cdot \Delta t}{\Delta z} \leq 1, \quad i=1, \ldots, N,
$$

where $w_{i}$ is the fluid velocity in the $i$-th node.

In a particular case, when $f(t)=\Delta T_{c z}$ the problem described by the Eqs. (1-5) has a strict analytical solution [18]:

$$
\frac{T_{c z}-T_{0}}{\Delta T_{c z}}=e^{-(\xi+\eta)} U(\xi, \eta),
$$

$$
\frac{T_{s c}-T_{0}}{\Delta T_{c z}}=e^{-(\xi+\eta)} U(\xi, \eta)-e^{-(\xi+\eta)} I_{0}(2 \sqrt{\xi \eta}),
$$

where $I_{0}$ is the modified Bessel function of the zero order and the $U$ is the function defined by the formula

$$
U(\xi, \eta)=\sum_{n=0}^{\infty} \sum_{k=0}^{n} \frac{\eta^{n} \xi^{k}}{n ! k !}
$$

In Eqs. (16-18) the following designations were adopted:

$$
\begin{aligned}
& \xi=\frac{z \cdot N_{c z}}{L_{r}} \\
& \eta=\frac{t-z / w_{c z}}{\tau_{M}}=\frac{t-\left(z \tau_{c z} N_{c z}\right) / L_{r}}{\tau_{M}}
\end{aligned}
$$

Eqs. (16-19) will be used to assess the accuracy of the finite difference method. In order to obtain a high accuracy of the analytical solution, the double series (18) was taken as $n>400$ in the computer calculations, as the series is slowly converging.

\section{Numerical simulation of steam pipeline heating}

The steam pipeline to be analysed is made of $13 \mathrm{HMF}$ steel. Its dimensions are as follows: length $L_{r}=48 \mathrm{~m}$, internal diameter $d_{i n}=0.217 \mathrm{~m}$, and wall thickness $g_{s c}=$ $0.028 \mathrm{~m}$. The physical properties of the pipe material are: density $\rho_{m}=7650 \mathrm{~kg} / \mathrm{m}^{3}$, specific heat $c_{m}=519$ $\mathrm{J} /(\mathrm{kgK})$ and thermal conductivity $\lambda_{m}=35 \mathrm{~W} /(\mathrm{mK})$. It has been assumed that superheated steam with temperature $T_{c z}=540^{\circ} \mathrm{C}$ and pressure $p_{c z}=11 \mathrm{MPa}$ flows suddenly into the pipeline. The steam thermal properties are - density $\rho_{c z}=28,492 \mathrm{~kg} / \mathrm{m}^{3}$, specific heat $c_{c z}=2484 \mathrm{~J} /(\mathrm{kgK})[19]$.

The initial temperature of the pipeline and fluid is $T_{0}$ $=300^{\circ} \mathrm{C}$. The value of heat transfer coefficient on the inner surface of the pipeline, for the preset flow velocity of the fluid $w_{c z}$, was calculated from the Dittus-Boelter correlation formula. The distribution of fluid temperature $T_{c z}$ and pipeline wall temperature $T_{s c}$ as a function of time was determined from the solution of the system of differential Eqs. (13-14) and analytical Eqs. (16-17).

The analysis of Figs. 2 and 3 shows that the finite difference method gives results with very good accuracy. It can be noticed that at higher steam speeds both the medium and the wall reach the steady state faster. Finite difference method can be applied for any changes in time of the medium temperature at the inlet and at temperature and pressure dependent thermal properties of medium and wall material. In such cases, it is difficult or impossible to find an analytical solution. 


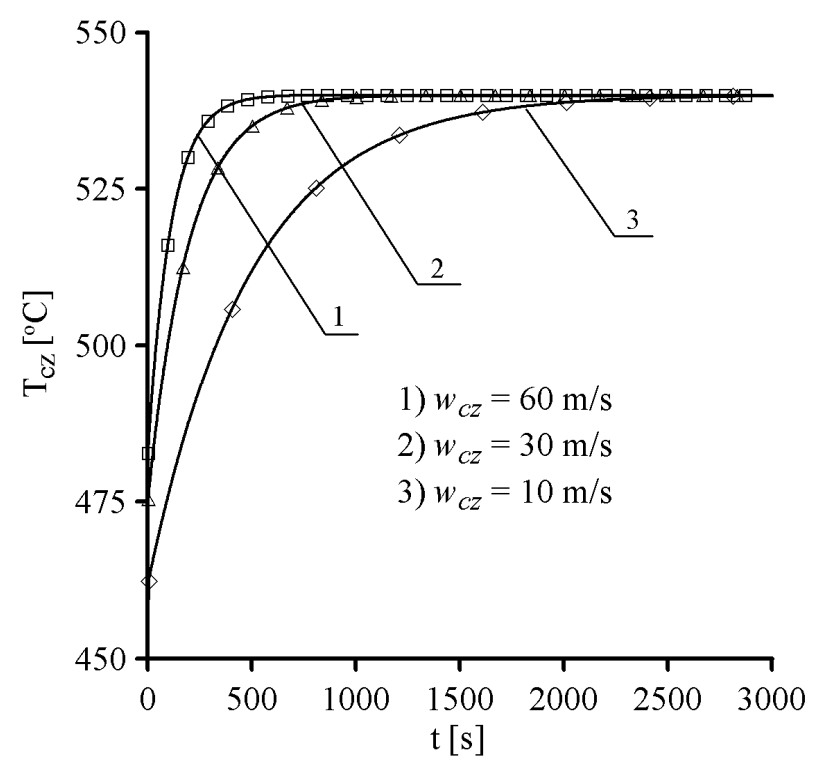

Fig. 2. Water steam temperature variation over time at the outlet from the pipeline for different steam flow velocities; the points are the values obtained by a strict analytical solution and the solid line temperature runs determined by the finite difference method

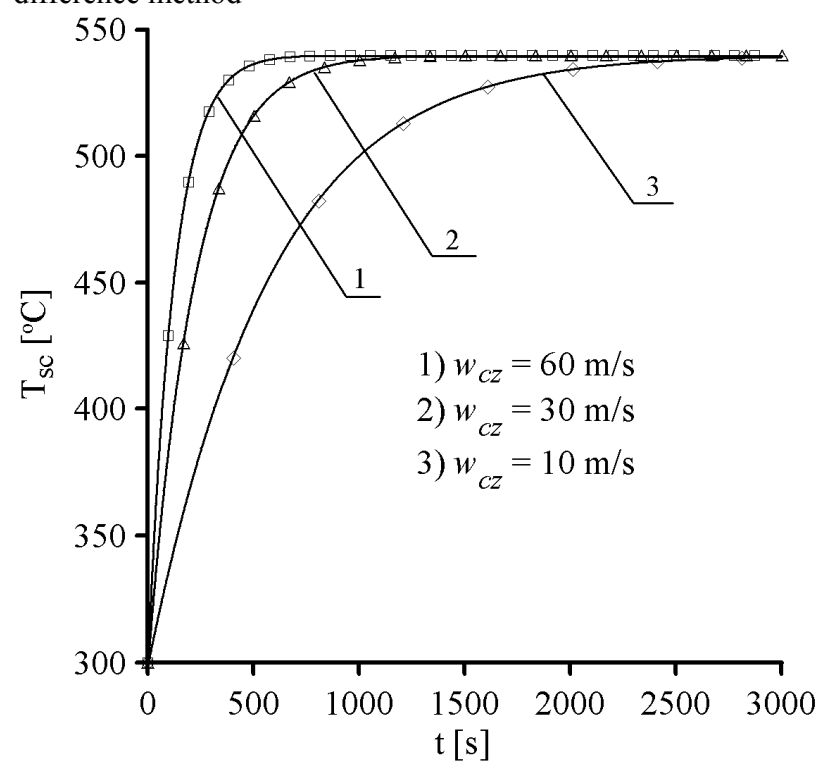

Fig. 3. Change in wall temperature over time at the outlet from the pipeline at different steam velocities; the points are the values obtained by a strict analytical solution, and the solid line temperature runs determined by the finite difference method

An example of transient courses of fluid and wall temperature caused by the linear increase of fluid temperature with constant speed $v_{T}=20 \mathrm{~K} / \mathrm{min}$ from initial temperature $T_{0}=300^{\circ} \mathrm{C}$ to final temperature $T_{k}=$ $540^{\circ} \mathrm{C}$ is shown in Figs. 4 and 5 . Calculations were carried out with the described explicit finite difference method. The analysis of Figs 4 and 5 shows that the pipeline heating speed is strongly influenced by the steam mass flow rate.

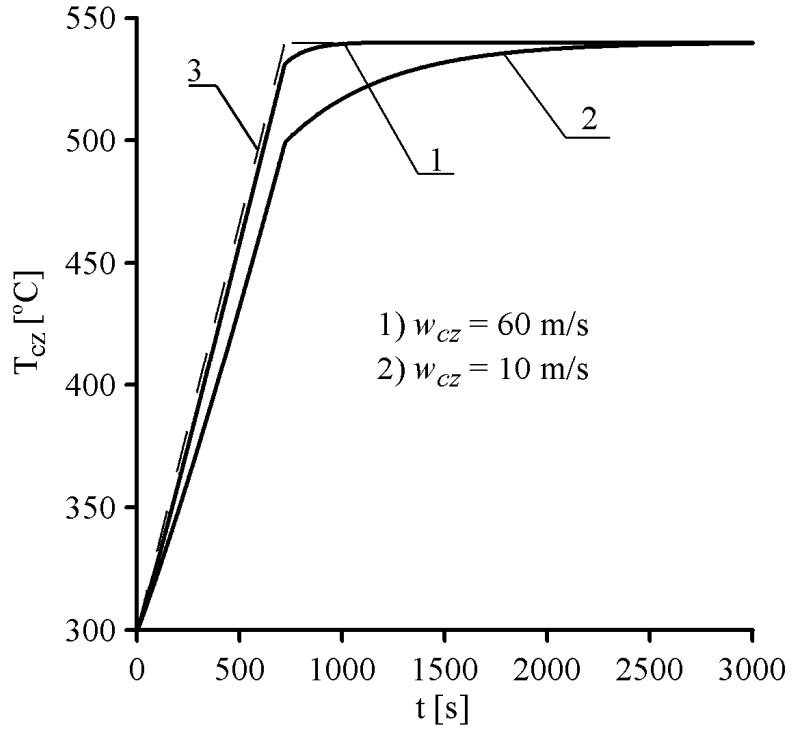

Fig. 4. Fluid temperature change over time at the outlet from the pipeline at different steam flow velocities and temperature change at the inlet to the pipeline described by the stepwise line - Eq. (3)

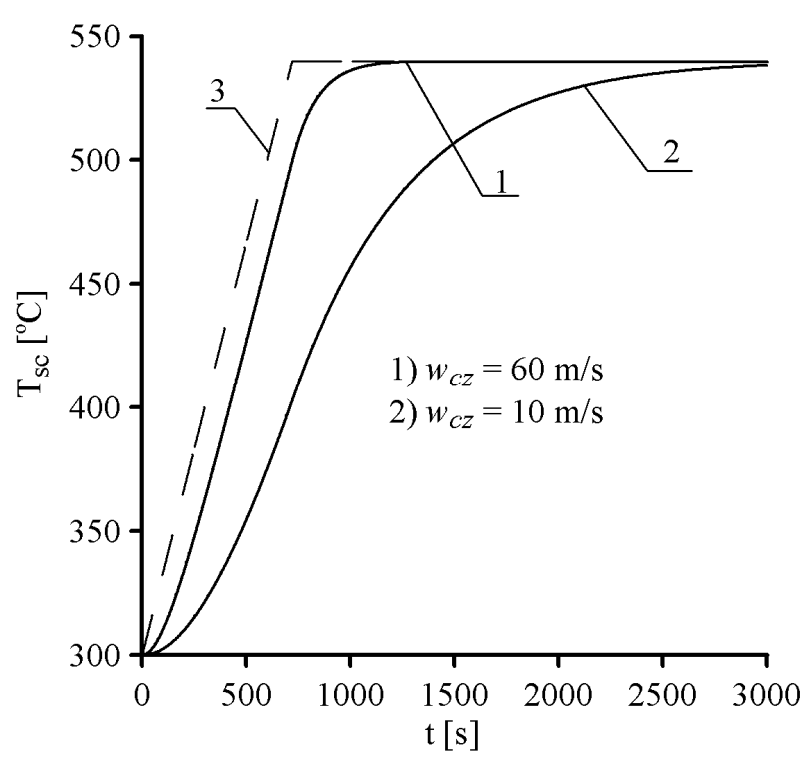

Fig.5. Change in wall temperature over time at the outlet from the pipeline at different steam flow velocities and temperature change at the inlet to the pipeline described by the stepwise line-Eq. (3)

If the steam flow velocity increases, the time of steam flow through the pipeline decreases and the heat transfer coefficient $h_{\mathrm{cz}}$ on the internal surface of the pipeline increases. Heat transfer coefficient increases from $h_{\mathrm{cz}}=$ $312,7 \mathrm{~W} /\left(\mathrm{m}^{2} \mathrm{~K}\right)$ at $w_{c z}=10 \mathrm{~m} / \mathrm{s}$ to $h_{\mathrm{cz}}=1311 \mathrm{~W} /\left(\mathrm{m}^{2} \mathrm{~K}\right)$ at $w_{c z}=60 \mathrm{~m} / \mathrm{s}$. The wall time constant $\tau_{M}$ decreases more than fourfold and the heating of the pipeline wall is much faster at $w_{c z}=60 \mathrm{~m} / \mathrm{s}$.

\section{Conclusion}

The explicit finite difference method presented in this paper can be used for the analysis of pipeline heating and cooling. A comparison of the calculated time histories of fluid and pipeline wall temperature with a stepwise 
increase in fluid temperature at the pipeline inlet with the histories obtained using strict analytical formulae shows that the accuracy of the differential method is very good. The finite difference method can be applied to any temporary changes in temperature of the medium at the inlet to the pipeline and depending on the temperature of thermo-physical properties of the medium and wall.

\section{References}

1. D.J. Littler (Ed.), Modern Power Station Practice. Volume $G$ - Station Operation and Maintenance. Third Edition (Pergamon Press, Oxford, 1991)

2. L. Cwynar, Rozruch kottów parowych (WNT, Warszawa 1981)

3. J. Taler, D. Taler, K. Kaczmarski, P. Dzierwa, M. Trojan, T. Sobota, Energy, 160, 500-519 (2018)

4. T. Sobota. Heat Transfer Eng., 39(13-14), 12601271 (2018)

5. T. Sobota, E3S Web of Conferences, 13, (2017)

6. T. Sobota, E3S Web of Conferences, 14, (2017)

7. J. Taler, B Węglowski, W. Zima, P. Duda, S. Grądziel, T. Sobota, A. Cebula, and D. Taler, Proc. IMechE 222 Part A: J. Power and Energy, 11-24 (2008)

8. J. Taler, S. Gądziel, T. Sobota, D. Taler, Archiwum Energetyki, XXXVIII(1), 97-122 (2008)

9. S. Lubecki, D. Taler, T. Sobota, Archiv. of Thermodynamics, 29 (4), 87-96 (2008)

10. J. Taler, Sz. Lubecki, T. Sobota, Energetyka, 2-3, 680-681 (2011)

11. J. Taler, B. Węglowski, T. Sobota, D. Taler, M. Trojan, P. Dzierwa, M. Jaremkiewicz, M. Pilarczyk, Proc. of the ASME 2016 Power Conference POWER2016, (2016)

12. T. Sobota, Testing station for computerized systems for continuous monitoring of power boilers' operation, in Modern Power Systems and Units, J. Taler (Ed.) (Wydawnictwo Politechniki Krakowskiej, Kraków, pp. 577-586 2007)

13. M. Jaremkiewicz, D. Taler, T. Sobota, Int. J. of Thermal Sci., 87, 241-250 (2015)

14. M. Jaremkiewicz, D. Taler, T. Sobota, Appl. Thermal Eng., 29, 3374-3379 (2009)

15. J. Taler, B. Węglowski, D. Taler, T. Sobota, P. Dzierwa, M. Trojan, P. Madejski, M. Pilarczyk, Energy, 92(1), 153-159 (2015)

16. J. Taler, D. Taler, T. Sobota, P. Dzierwa, Archiv. of Thermodynamics, 32 (3), 103-116 (2011)

17. P.H. Oosthuizen, D. Naylor, Introduction to Convective Heat Transfer Analysis (McGraw-Hill, New York, 1999)

18. E.P Serov, B.P. Korolkov, Dinamika parogienieratorov. (Energoizdat, Moscow, 1981)

19. ASME Steam Tables. Sixth Edition (The ASME, New York, 1993) 